\title{
Analysis of the College Students' Online Entrepreneurship
}

\author{
HaiLan Pan ${ }^{1,}$, CuiHong $\mathrm{Wu}^{1, \mathrm{~b}}$ and ShiWei Lin ${ }^{1, \mathrm{c}}$ \\ ${ }^{1}$ School of Computer and Information, Shanghai Second Polytechnic University, Shanghai 201209, \\ China \\ apanhailan@sspu.cn, ${ }^{b}$ chwu@sspu.cn, ${ }^{\text {c}}$ swlin@sspu.cn
}

Keywords: E-commerce, entrepreneurship, business policy, business law, college students.

\begin{abstract}
At present college students' employment becomes a hot social problems, and through a survey on college students online business-related issues, this paper analyzes the factors affecting online business, including financial, online business environment, the implementation of the policy, one's own reasons, and to summarize several common ways about e-commerce online entrepreneurship, in which to manage an online shop is particularly prevalent. Therefore, the paper analyzes the advantages and potential obstacles in details, and finally to discuss these issues and put forward suggestions and countermeasures for entrepreneurs.
\end{abstract}

\section{Introduction}

In recent years, with greatly increasing number of college students, the employment of college graduates has been hot social problems. But the sustainable development of the Internet and e-commerce is booming, giving college students a good opportunity [1]. Internet entrepreneurship has become a new choice for students to solve the employment, thus, students gradually have feelings and thoughts on entrepreneurship. But due to the entrepreneurial environment and experience for cable restrictions, many people start on the road will encounter great obstacles.

\section{Survey and Analysis}

The online survey lasted for over one month, and received 123 valid respondents. More than half of the surveyed population were from e-commerce professional students, and the rest of them were from other professional; the respondents were mostly university degree; and male to female ratio was approximately 1:1.

Understanding of Entrepreneurship. The survey noted the idea of entrepreneurship: "Like very much", "A little", "Having not considered". The proportion of three respectively was $13.82 \%$, $65.04 \%$, $21.14 \%$. More than $80 \%$ of college students had ideas of online business. The idea is the emotional thinking in one's mind, driving you to do something. At this time, generally, people have not considered about any results [2].In the final survey results, $21.77 \%$ of them had not considered to entrepreneurship. It is enough to see the idea of entrepreneurship is developing in college students minds.

Everyone has their own methods to achieve the purpose. Students would like to start their business by the network, which is one of the methods. We can see people have different starting points in the survey. $25.77 \%$ of the people think that online business is easier to make money. Between wealth and self-worth, about a quarter of the students blindly value the wealth, which is understandable, but it is very rational. Students who have high expectations for entrepreneurs are fairly one-sided. They ignore the entrepreneurial risk. They think that as long as they open shops they must will be successful.

The Main Factors Influencing Entrepreneurship. Referring with table 1, the funding for entrepreneurship is the material basis. Not having financial support, we will be hard to start business .College students have no income, so venture capital is a problem. College students 
generally do not have a lot of deposits, so they have to rely on his family, and thus, the majority of students which want to venture are facing great obstacles.

Table 1. Factors influencing entrepreneurship

\begin{tabular}{|c|c|c|l|l|l|}
\hline $\begin{array}{l}\text { Sources of } \\
\text { funding }\end{array}$ & $\begin{array}{l}\text { Online business } \\
\text { environment is } \\
\text { not good }\end{array}$ & $\begin{array}{l}\text { Family attention and } \\
\text { support is not enough }\end{array}$ & $\begin{array}{l}\text { Fear of } \\
\text { failure }\end{array}$ & $\begin{array}{l}\text { Government policy } \\
\text { is not effective to } \\
\text { implement }\end{array}$ & Others \\
\hline $60.92 \%$ & $70.73 \%$ & $44.72 \%$ & $68.29 \%$ & $55.28 \%$ & $21.14 \%$ \\
\hline
\end{tabular}

The entrepreneurial environment is very complex, covering many aspects. To create a good entrepreneurial environment can make the process of entrepreneurship among university students is not so difficult; otherwise, it will limit the students to entrepreneurship. Today, with the high-end technology, hackers and other criminals make crimes through network vulnerabilities, and go unpunished. It makes buyers and sellers bear property damage. Although the Government has introduced electronic contracts, online payments and other legal norms, but it is still in initial stage. To standardize network security, there is still a long way to go.

There are a lot of entrepreneurship policies, but the survey shows: $30.02 \%$ of the students did not know totally, while $62.89 \%$ of the students had heard of some, but not to learn more about them. This shows in front of the college students' entrepreneurship, they do not have system awareness and planning to all aspects of the entrepreneurship, and they don't have preliminary preparation.

It is understandable that students are afraid of failure in entrepreneurship. In an increasingly competitive environment, the survival of the fittest is the inevitable law. When you are faced with such situations, fear is inevitable. Fear of failure is usually only in your head, which is adding unnecessary trouble in front of the unknown results. Usually, that most of the entrepreneurs have Fears and concerns is normal in the early. Put it bluntly, and it looks terrible, in fact, nothing terrible. It depends on how you look at it.

Access to the Way of Entrepreneurial Knowledge and Skills. There are many ways to know about the entrepreneurial knowledge and skills. Everyone can start entrepreneurship in different aspects. In this survey, it is not difficult to find that a lot of people are willing to practice by themselves because entrepreneurship must go hand experience, to sum up experience. Also a lot of people would like to ask to experienced people for help, or turn to entrepreneurial agency guidance for help, or participate in a variety of entrepreneurship competitions to accumulate experience, and also want be educated about entrepreneurship by teachers.

Analysis of Entrepreneurial Way. The way to Online entrepreneurship are varied, in the survey we have discussed several basic forms: online shops, personal websites and commercial websites.

Which ranks first is online shops on the third-party trading platform, accounting for $71.54 \%$ of the total. Managing an online shop is an entrepreneurial form which college students like best. Today managing shops on Taobao, Dangdang etc. is common. It is less to put into an online shop. The mode of operation is flexible, and it can provide good profit margins. But it also needs to do a lot of work, including preparation, supply, and publicity.

The second is to create a personal website, accounting for $14.63 \%$ of the total. In general, many personal websites initially were established is just out of an interest or hobby. With the promotion of time, the websites will accumulate a lot of resources, and website traffic is great. Business-minded people will cooperate with business enterprises to put their advertisements on the websites. But to entrepreneurship in this way, it must be time-based, and entrepreneurial cycle is long.

$8.94 \%$ of people choose to commercial websites. To set up commercial websites is for profit. Of course, commercial websites are very different from online shops and personal websites. For a complete business website, it needs to make all aspects of comprehensive planning and assessment. The large investment in the early is difficult for college students to bear.

Analysis of the Reasons for Managing Online Shops. Online marketing is convenient, with less cost. The big advantage of the online shops is convenient marketing, and the cost is low. Internet marketing in propaganda costs less, compared with traditional marketing. Don't have to spend a lot of human, material and financial resources. As long as people make use of its propagation speed and 
scope to advertise products through the Internet, which can greatly reduce the cost of marketing, and can achieve good publicity effect.

Entry threshold is low and investment is small, and has advantage of the Price. For ordinary college students, setting up an online shop is easiest to accept because of the low entry threshold. Most people want to turn to a third party trading platform, such as Taobao. Online shops depend on clicking a mouse to accomplish an order, and necessary communication with customers. Online shops need less input and recovery quickly, and some shops are agents, having manufacturers to provide goods. They do not need to worry about the problems of goods source, and do not need to worry about goods in stock cause loss. What's more, the goods in online shops is always cheaper than those sold in entity shops, because the cost of investing entity shops is more. The sellers will pay a lot of extra fees, lease fee, renovation fee, and water and electricity cost, but we don't have to consider these issues in online shops. Due to the low price of goods, the sellers can make the small profits and quick turnover, which can attract more customers' eyes.

Online shops can be away from time and space restrictions. Online shops are different from entity shops. Online shops are not limited that no matter where the customers are, as long as they can get to the Internet, and customers can browse the web, they all can buy things. And as for the sellers, in the face of a big market, the entire Internet users are their potential customers.

Setting an online shop is simple, and easy to do. In surveys many students see it is easy to open a shop, indeed, the threshold of setting an online shop is low. Now if someone wants to open an online shop on the net, he or she only needs to complete some relatively simple requests, then he or she has a personal online shop. But it is necessary to know managing online shop is a business, and is certainly a risk. It is not necessary that someone who put some money on it would have a good return. It is easy to open a shop, but it takes more energy to business.

Influence Factors of Setting Up Online Shops. The newcomers are lack of experience, and credit is not high. College students start to entrepreneurship by setting shops on the net. They may tend to think that starting to entrepreneurship is idealistic process. They have high expectations to the return [2]. But in fact, a new seller will face more difficulties. For example, the two same goods, one is a new seller and the other is a crown seller. In the ordinary people's eyes, it is sure to choose the high reputation, because they feel more reliable. Therefore, because the new sellers have no rich experience, and credit is not high, they will be out of business [3].

Online Competition is intense. It is not so easy to set up an online shop as we think. Although the entry threshold is low, not everyone can get success. Now, such as Taobao, it has numerous sellers. The market is big , but due to the low entry threshold, entrepreneurs is easy to enter the field [4]. There are hundreds and thousands of sellers selling same goods. For the newcomer, we can imagine how fierce the competition is.

Student are afraid that no one buys his goods and goods are in stock, then, they have to bear the losses themselves. College students have no rich material wealth. If they want to invest setting online shops, they have to worry about if they will be failed in their business. If they get success, it is very good, but if sales are poor, they have to take responsibility themselves. For college students ,they hardy bear the risk of such.

\section{Countermeasures and Suggestions}

To Rationally Analyze Problems, and Place Correct Mindset of Entrepreneurship .There are many cases of failure in business. At the beginning, most students are confident, and be full of ambition to start a business. But when one after another setbacks are brought out, it is powerless for them to face and give up. People who want to get success in business under a competitive environment not only need to rely on good entrepreneurial knowledge and skills, but also depend on the ability of overcoming setbacks.

For entrepreneurial speaking, it should be suitable for one's ability and interest, and college students should not be blind to follow. After we have the idea of entrepreneurship, the rational analysis is necessary. We can not escape because of the fear of failure, and should have the 
psychological burden to the risk, and must place correct mindset of entrepreneurship. Having basic knowledge and skills needed for entrepreneurship, please avoid acting recklessly. At this time, college students should avoid being blunder, or business is started today, and no one knows which day it is away.

University's Task to Help College Students' Entrepreneurship. Now the colleges are lack of attention to develop students' awareness of entrepreneurship. For college students which want to start to entrepreneurship, entrepreneurship education and guidance training is an ignored link currently. Generally, Short-term training is set in the colleges, but it is set for some major professional courses. As a breakthrough, colleges can organize teachers to teach the basic entrepreneurship knowledge and skills in the short term. Different professional students interested can join in, and learn from each other and mutual cooperation. This way can improve students' basic entrepreneurship skills. Colleges can also open courses related with entrepreneurship, and introduce some teaching equipment. It will produce a subtle influence on college students' entrepreneurship.

To Carry National Policies into Practice. Our country has issued a series of policies to support college students' entrepreneurship, and they provide a lot of help in the process of entrepreneurship [5]. The launches of the policies are good in theory, but the actual implementation effect is not beautiful. Therefore, the government should pay attention to combination of the theory and the reality to create a good environment of online entrepreneurship.

Law Improved Constantly. Although legal specifications such as the electronic contract, online payment, have been introduced, it is still in the initial stage, and it still exists a lot of legal loophole. Our country should continue to improve the laws related to the e-commerce business, in order to provide a secure network environment.

\section{Conclusions}

In the Internet age, more and more college students choose to start their own businesses, and online business has become a new trend of solving the employment problem. Setting up online shops is accepted by college students in the advantage of the low entry threshold. For colleges, they can provide guidance to the students who need, and support for students' entrepreneurship. Before entrepreneurship, besides to learn professional knowledge, students also need social practice and summarize the experience.

\section{References}

[1] Wang Guoyu , Zeng Xianjie, and He Yihui etc. the Research of College Students' Employment and the intent of business [J]. China youth research study. Vol. 12 (2011), p. 28-44.

[2] Cheng Xinping. The Thinking of Improving College Students' Entrepreneurship Consciousness and Ability of Employment Under the New Situation [J]. Education and professional, Vol. 27 (2007), p. 179-180.

[3] Zhou Changqing. College students' online careers and risk analysis [J]. Science and technology startup issue, Vol. 9 No. 16 (2010), p. 40-41.

[4] Chao-Jung Hs . Dominant Factors for Online Trust, C. International Conference on Cyberworlds, Vol. 7 (2008), p. 65-71.

[5] Mauro F. Guillen and Sandra L. Suarez, Developing the Internet f entrepreneurship and public policy in Ireland, Singapore, Argentina, and Spain [J]. Telecommunications Policy, Vol. 25 (2011), p. 2. 